\title{
Umbilical Artery
}

National Cancer Institute

\section{Source}

National Cancer Institute. Umbilical Artery. NCI Thesaurus. Code C33827.

A pair of arteries occurring during embryonic development that are the continuation of the internal iliac artery which carry deoxyg enated blood from the fetus through the umbilical cord to the placenta. 